Final submitted and accepted version

Reichenberger, I. (2017). C2C value co-creation through social interactions in tourism. International Journal of Tourism Research, 19(6), 629-638.

\title{
C2C VALUE CO-CREATION THROUGH SOCIAL INTERACTIONS IN TOURISM
}

\section{KEYWORDS}

co-creation; social interactions; social situation analysis; visitor experience; value; social practice

\begin{abstract}
This paper examines the social practice of customer-to-customer value co-creation in tourism contexts by considering visitor-visitor interactions, their manifestations, influential factors, and types of resulting value using extended social situation analysis. Based on 76 qualitative indepth interviews, results show that value co-creation is not necessarily dependent upon the underlying social interactions but predominantly influenced by personal factors and attitudes towards sociability. The stronger the focus on other social actors is, and the longer and more personal the social interactions are, the more complex and multilayered is the co-created perceived value.
\end{abstract}




\section{INTRODUCTION}

Although tourism is often considered ,an individualistic practice, sometimes solitary, even selfcentred, it is frequently not so" (Crouch, Aronsson, \& Wahlstrom, 2004, pp. 284-285). Tourism, more often than not, occurs with or alongside other people, resulting in constant encounters and consequently in people's ability to influence others and potentially alter an experience (Crouch et al., 2004). Tourists' interactions with places, locals, and also fellow tourists, can contribute greatly to the visitor experience (e.g. Cutler \& Carmichael, 2010; Maunier \& Camelis, 2013; Mossberg, 2007; Pearce, 2005a, 2005b; Walls \& Wang, 2011). Nevertheless, academic research often neglects the role that social components can play for travellers - "on the ground that this factor often is beyond control of the organizations" (Mossberg, 2007, p. 68).

In recent years, this has been addressed by co-creation in a tourism context. However, the cooperative creation of experiences between visitors has received only limited attention, as most research is concerned with the co-creation of experiences between service organisations/providers and customers (Andrades \& Dimanche, 2014; Campos, Mendes, do Valle, \& Scott, 2016; Rihova, Buhalis, Moital, \& Gouthro, 2015). Customer-to-customer (C2C) co-creation has been linked to higher guest satisfaction and loyalty (Mathis, Kim, Uysal, Sirgy, \& Prebensen, 2016) and is based upon tourists' active participation and interaction with social actors (Campos, Mendes, do Valle, \& Scott, 2015). Empirical confirmation of these interactions however is still mostly lacking. The identification of factors contributing to co-creation through interaction and participation and their practical manifestations are, however, crucial in deepening our understanding of the subjective, experiential perspective of value co-creation in tourism. Especially in light of continuously increasing visitor numbers and future forecasts (World Tourism Organization, 2010), higher usage of tourism infrastructure is to be expected, in turn leading to higher user densities within tourism settings. As the visitors' proximity within shared spaces increases, so does the potential as well as the necessity for social contacts and thus $\mathrm{C} 2 \mathrm{C}$ co-creation.

This paper discusses $\mathrm{C} 2 \mathrm{C}$ co-creation in a tourism context by examining the manifestations of social interactions and the perceived value stemming from co-creating experiences with other visitors. More specifically, it analyses the components and characteristics of interactions between tourists as well as their influential factors. Furthermore, this paper examines the perceived types of value co-created through visitor-visitor interactions. In summary, this paper will answer the following research questions: "How are social interactions between visitors manifested?", "Which factors influence social interactions between visitors?", "How can these interactions be categorized?", and "What is the perceived value co-created through social interactions with other visitors?"

To do so, this paper first presents literature on tourism-related $\mathrm{C} 2 \mathrm{C}$ co-creation and social interactions within tourism settings and highlights a theoretical conceptualization of customerbased value co-creation. It then introduces an extended social situation analysis as a framework to empirically verify the components of the conceptualization in order to comprehensively illustrate value co-creation between tourists. 


\section{C2C CO-CREATION IN TOURISM}

Tourists are not passive elements of their respective settings, but active participants who organize and construct their social world and experiences (Pearce, 2005b). They are thus cocreators of their individual experiences (Prebensen, Vitters $\varnothing$, \& Dahl, 2013) and their subjectively perceived value (Li \& Petrick, 2008), which does not stem from a product or object but from the consumption experience itself (Holbrook, 1999). Co-creation builds upon service dominant logic (Vargo \& Lusch, 2004), arguing that value only then comes into existence once the consumer utilizes the service a product is designed to provide. Therefore, "value is always co-created, jointly and reciprocally, in interactions among providers and beneficiaries through the integration of resources and application of competences" (Vargo, Maglio, \& Akaka, 2008, p. 146). In tourism, the concept has been used predominantly to examine the co-creation of value between tourists and service providers to aid the tourism industry in delivering memorable experiences not only to but with customers (Andrades \& Dimanche, 2014). Here, co-creation is considered "a process of interrelated interactions and activities that connects the tourist and other actors, and experiences are the context in which those interactions and activities occur" (Campos et al., 2016, p. 3). Value is thus created through social practice (Rihova et al., 2015); social practice in turn requires active participation and interaction with others (Prebensen \& Foss, 2011; Tan, Kung, \& Luh, 2013). Prior research on co-creation in tourism has focused predominantly on interactions between customers and service providers (e.g. Cabiddu, Lui, \& Piccoli, 2013; Neuhofer, 2016; Prahalad \& Ramaswamy, 2004; Shaw, Bailey, \& Williams, 2011; Vargo et al., 2008), with only selected studies focusing on the experiential and behavioural tourist perspective and the interactions between visitors only. Rihova et al. (2015) developed a conceptualization of $\mathrm{C} 2 \mathrm{C}$ value co-creation in tourism (see Figure 1, adapted to remove practical implications).

\section{Insert Figure 1 here}

The core of value co-creation processes consists of social practices, referring not only to social behaviour but viewing tourist, social and physical context as one entity (Warde, 2005). Social practice, created through social interactions, is suggested to be influenced by personal resources, the interpretation of shared images, and social structures. Social practices differ depending on their respective level, representing visitors' different social contexts and providing an approach for categorizing visitor-visitor interactions. The communitas level signifies a sense of togetherness between tourists sharing an experience, the social bubble refers to social practice between previously acquainted tourists, and the detached tourist level includes those who do not seek contact with unacquainted social actors (Rihova et al., 2015; Rihova, Buhalis, Moital, \& Gouthro, 2013). Social practice within these levels then creates value. This theoretical framework has not yet been empirically verified, although Campos et al. (2016) confirmed the contribution of social interactions to value co-creation through positively impacting enjoyment and memorability, thus shedding light on what value can represent to tourists. However, numerous authors emphasize the need for a more holistic understanding of tourist experiences, especially highlighting the need for insight into the manifestation of social practices underlying C2C value co-creation and empirical verification of influential factors (Campos et al., 2015; Campos et al., 2016; Rihova et al., 2015; Rihova et al., 2013). In order to fill this research gap, further studies on the social components of tourism can contribute to our understanding of 
social interactions between tourists as the foundation for value co-creation through social practice.

Several studies examine social contacts within tour group settings (Fisher \& Price, 1991; Ross $\&$ Iso-Ahola, 1991). An extroverted and positive attitude, high assigned importance to the social aspect, and frequent and positively perceived social interactions with other tour group participants were found to be essential components of tours (Heimtun, 2011; Levy \& Getz, 2012; Quiroga, 1990; Ross \& Iso-Ahola, 1991). Interactions are also encouraged by environmentally restricted settings (Holloway, 1981; Levy \& Getz, 2012; Tucker, 2005). Schuchat (1983) determined a ritualized conversation pattern between tour group members, which was also observed in transport and accommodation settings (Harris \& Baron, 2004; Murphy, 2001). These patterns contribute to the establishment of familiarity while being dependent upon commonalities between interaction participants. Enjoyment of social interactions within tour groups and/or positively perceived behaviour of other group members was found to increase satisfaction with the experience (Levy \& Getz, 2012; Quiroga, 1990; Wu, 2007). Although the environmental 'bubble' of tour groups provides a unique interaction setting (Cohen, 1972) in terms of physical proximity, heterogeneity, and shared circumstances (Quiroga, 1990), the personal attitude of visitors towards the social aspect as well as the environmental and contextual circumstances of interactions, are likely to also impact social interactions in a wider tourism context.

Further studies were conducted in settings such as home stays (Pearce, 1990), theme parks (Grove \& Fisk, 1997), backpacker hostels (Murphy, 2001), railway transport (Harris \& Baron, 2004), and cruise ships (Huang \& Hsu, 2010; Papathanassis, 2012). Especially the relevance of the environmental setting for encouraging or discouraging interactions has been confirmed. Social interactions between consumers in service settings (Baron, Harris, \& Davies, 1996; McGrath \& Otnes, 1995; Parker \& Ward, 2000) underlie comparable factors: the environmental service setting, presence and behaviour of service employees as well as individual consumer characteristics all impact the occurrence of $\mathrm{C} 2 \mathrm{C}$ social interactions and the subsequent satisfaction with the retail experience (see Nicholls, 2010 for an overview).

Hitherto existing research does not yet foster an in-depth understanding of influential factors and value-related effects of interaction based social practice from a wider, tourist-centered perspective. Yet they draw attention to aspects not considered in Rihova et al.'s (2015) C2C value co-creation conceptualization (such as the physical environment) and provide suggestions for more specific identification of especially personal resources. In order to fill the research gaps on social practice and its contribution to $\mathrm{C} 2 \mathrm{C}$ value co-creation, this study will thus employ an extended social situation analysis to examine the social interactions underlying social practice within a more comprehensive framework. It aims to identify the manifestations of social interactions within the previously identified social practice levels, illustrate the impact of influential factors, and identify the type of value that is co-created.

\section{SOCIAL SITUATION ANALYSIS}

Analysing the social interactions contributing to $\mathrm{C} 2 \mathrm{C}$ value co-creation calls for an understanding of the complex processes influencing them. A framework developed specifically 
to understand social interactions is social situation analysis (Argyle, Furnham, \& Graham, 1981), a social psychological approach aiming to deconstruct interactional behaviour of individuals through identifying structure and elements of social interactions; previously shown to be applicable to interactions within tourism settings (Murphy, 2001; Pearce, 1984, 1990). Social situations consist of interconnected features (roles, environmental setting, goals, repertoire of elements, sequences, rules, concepts and cognitive structures, language and speech, see Table 1), whose interplay structures and determines social situations and the social interactions occurring within. Originally only concerned with generalizable reciprocities and connections, traditional social situation analysis takes a purely positivist approach in deconstructing the complexities of social situations. The concept of co-creation however stems from the assumption that meaning (including value) is, in its creation and interpretation, fully dependent upon social actors, thus adopting a social constructivist approach to explore "the meaning-making activity of individuals" (Pernecky, 2012, p. 1132). Yet individuals are not integrated in or relevant for social situation analysis, which is why social situation features alone do not provide sufficient insight into the reality of social interactions for co-creation. Being limited by their focus on the abstract phenomenon of a social situation itself, they fail to take into account "the social and contextual understanding of [...] life" (Hollinshead, 2006, p. 44). Social and contextual aspects, however, are a crucial component of social interactions and thus co-creation (Rihova et al., 2015), calling for modification of the original nine features of social situations to adapt to the social constructivist perspective required to answer the research questions.

Although the originating positivist paradigm underlying social situation analysis does not - at first glance - correspond to the approach taken for this research, it does when enhanced by and interpreted in connection with additional features. Through this, it aids the investigation of social interactions in the experiential co-creation of value while simultaneously acknowledging that knowledge, meaning and reality are actively constructed by individuals through social processes ( $\mathrm{Au}, 1998)$. The shared images, proposed as an influential factor for social practice and thus interactions by Rihova et al. (2015), are represented by the feature of concepts and cognitive structures. Social structures are then addressed by the features of roles, repertoire of elements, sequences and rules, as these contribute to the acceptance, order and processes of interactional elements. The original feature of the environmental setting addresses an aspect neglected by Rihova et al. (2015), yet identified as an important factor in prior research on social interactions in tourism settings (e.g. Levy \& Getz, 2012; Murphy, 2001; Quiroga, 1990). Goals and language/speech then refer to the individual personal resources. This factor however requires an extension to take into account previously discussed components such as personality or social attitudes (e.g. Harris \& Baron, 2004; Heimtun, 2011; Ross \& Iso-Ahola, 1991) - the additional feature of 'individual traits' is added to the original social situation analysis, thus enhancing the framework's ability to go beyond a positivist approach and enable the integration of individual meaning as required by social constructivism. In order to fully acknowledge the reciprocal nature of social interactions between visitors, a second additional feature 'interaction partner relationship' is added, based upon studies emphasizing factors such as commonalities/heterogeneity (e.g. Harris \& Baron, 2004; Quiroga, 1990) in being crucial determinants for interaction perception and acknowledging the co-operative creation of value.

Table 1: Enhanced features of social situations (adapted from Pearce, 1990, p. 342) 
The extended features of social situations shed light on the manifestations of social interactions and their influential factors. They provide an initial structure for data collection while being enhanced through individual aspects that then allow for the subjective, experiential and individualistic interpretation of interdependencies and potential outcomes that will illustrate the types of value that can be gained from $\mathrm{C} 2 \mathrm{C}$ co-creation. It aids to identify potential components of the proposed factors influencing social practice and its interactions (see Figure 1, personal resources, shared images, social structures) and acknowledges the role of the physical context (Warde, 2005).

\section{STUDY METHODS}

Social constructivism emphasizes the subjectivity of lived experiences and regards reality as a self-created mental construction, developed through social practice and experiences (Small, 1999). As any findings are the result of an interaction-based co-creational process between researcher and subjects, and the main focus is on understanding individual interpretations of reality (Lincoln, Lynham, \& Guba, 2011), a qualitative approach was adopted for this research. This also addresses potential gaps and weaknesses in both frameworks underlying this research - neither the conceptualization of $\mathrm{C} 2 \mathrm{C}$ co-creation nor the extended social situation analysis have been tested empirically and hermeneutical approaches to data collection allow for the emergence of unpredicted aspects. Qualitative interviews were chosen, as these have been utilized successfully to apply social situation analysis to tourism contexts (Murphy, 2001; Pearce, 1984, 1990) as well as in interaction-based co-creation (Campos et al., 2016).

A total of 76 in-depth interviews were conducted during the summer season (November to April) in the visitor information centres of Rotorua and Wellington, New Zealand, to avoid a potential bias based on location, interest or travel style. Both facilities offered an integrated café where research participants were offered refreshments and snacks while providing seating and a relatively private setting. Potential participants were chosen by structured sampling and personally approached by the researcher when leaving the premises, so as not to interrupt them during their search for information or booking process. The researcher was located at the main exit and, at quieter times, approached every visitor leaving the premises. At busier times with an increase in user density, the next available visitor was approached. Interviews lasted between 30 and 60 minutes, which led to single and couple travellers being overrepresented within the sample as larger groups were often not willing to wait for interview completion.

As in social constructivism knowledge the researcher is not an objective, distant data collector but an active participant in the creation of knowledge, and both participant and researcher have equal control in the creation process (Lincoln et al., 2011), the interviews were not visibly structured to participants. Instead, they were informed about the purpose of the study and its objectives and initially provided self-selected information on their experienced social interactions with other visitors. Through this, it was not the researcher who determined which particular social interactions and which touristic contexts were relevant for this study, but participants - although they were advised to reflect upon relatively recent experiences to reduce potential recall issues. Examples of $\mathrm{C} 2 \mathrm{C}$ social interactions nearly exclusively referred to focused and co-operative interactions (Goffman, 1967) in the form of verbal conversations with 
other visitors, thus providing an explicit and clearly defined core of how social practice is created. The researcher then ensured to draw out the relevant components of the extended social situation analysis in the context of specific social interactions with a particular focus on understanding the role of the individual, interdependencies of various factors and their role for perceived value.

Interviews were recorded and, as a first step in data analysis, transcribed, including paralinguistic aspects to enhance meaning. In a second step, transcripts were transferred to the analysis software NVivo, where contents were coded twice, according to the two frameworks underpinning this research. First, knowledge was assigned to the components of Rihova et al.'s (2015) C2C co-creation conceptualization (see Figure 1), more specifically (a) personal resources, (b) shared images, (c) social structures, (d), social levels, and (e) resulting value. In a second independently undertaken step, transcripts were coded according to the extended social situation analysis (see Table 1). During the third step, it was tested whether the affiliations between both framework components as discussed previously are applicable, and what the interdependencies between influential factors, the social interactions as core manifestation, and participant characteristics were. In the fourth and final step, value as a result from interactional $\mathrm{C} 2 \mathrm{C}$ co-creation was examined in terms of what forms of value were reported and what these depend upon.

\section{STUDY FINDINGS}

Table 2 presents the demographic characteristics of research participants as well as their travel behaviour. All participants were independent travellers on a self-drive holiday due to New Zealand appealing predominantly to this particular segment. Based on a combination of long travel duration, shared accommodation and public transport (Becken \& Gnoth, 2004; LokerMurphy \& Pearce, 1995; Murphy, 2001), slightly over half of the sample are backpacker travellers (predominantly single) while the remaining half are smaller groups of independent travellers with a preference for private accommodation and transport and comparatively shorter lengths of stay. Group or package travellers and families with children found themselves unable to participate in this research due to time constraints.

Table 2: Sample typology and characteristics (*multiple responses possible)

The following sections will display the findings based on extended social situation analysis integrated in the conceptualization of $\mathrm{C} 2 \mathrm{C}$ value co-creation. Due to the complexities and interdependencies within these combined frameworks, the presentation of results will be structured according to the original research questions. The first question, "How are social interactions between visitors manifested?", will be answered by looking at origin and processes of visitor-visitor interactions, drawing on social situation features where necessary to illustrate reasons and meaning behind them. In a second step, "Which factors influence social interactions between visitors?" will be structured according to the three levels of social practice to 
simultaneously answer the question "How can these interactions be categorized?". Here, social situation features that impact origin and processes will be drawn together. The final question, "What is the perceived value co-created through social interactions with other visitors?", will then draw upon the previously discussed information to illustrate the potential variety of perceived value on the visitor experience - taking into account both singular social interactions and their cumulative effect.

\section{Manifestations of C2C Social Interactions}

When illustrating social interactions with other visitors, it emerged that the original motivation to engage in them could be divided into intrinsic and extrinsic goals; the first referring to the joy and pleasure that stems from social contacts, the latter based upon perceived obligations due to politeness or a need for information or help. The roles attached to being a tourist - most specifically perceived increased sociability - appeared to be universally understood amongst participants and contributed to the origin of social interactions:

We like meeting people and enjoy mixing with others, and being a tourist makes it quite easy, it's what you do, people expect you to, as opposed to, you know, at home. There, it's quite frowned upon to address strangers.

Female, UK

The actual manifestation of $\mathrm{C} 2 \mathrm{C}$ social interactions was exclusively determined by social structures. The repertoire of elements deemed appropriate for social interactions in a tourism context, as well as a particular sequence of behaviour, led to a strict conversational pattern (as confirmed by Harris \& Baron, 2004; Murphy, 2001; Schuchat, 1983) often referred to as 'social protocol'. While interactions with extrinsic goals first aimed to fulfil said goal, it was then expected to continue as follows: Enquiring about country of origin, past and future travel itineraries within New Zealand and travel recommendations.

It's usually where are you from, where have you been, what have you done, where are you going. People will give you tips, go here, don't go there, that was good, this was bad.

\section{Male, Australia}

These themes may then be enhanced by circumstantial factors relating to the current experience within which interactions occurred, such as sharing perspectives and perceptions, drawing on comparable experiences or the respective home countries. Commonly accepted rules require adherence to the previously discussed patterns before enhancing the interaction with more personal and private components, as otherwise interactions were easily perceived as intrusive and uncomfortable and were terminated prematurely. All participants expressed an understanding of the concepts and cognitive structures that regulated visitor-visitor social interactions in a strict manner through shared images. 
In summary, the observable manifestation of social interactions with other visitors emerged as both predictable and seemingly mundane, often without apparent co-creational benefits when described as fleeting, forgettable and short in duration.

It's more superficial, I think it's also because of the time pressure. We don't have much time here, so our conversations with others are mostly short, we talk about our travels, about recommendations, but there's no time to really get to know people.

Female, Netherlands

Nevertheless, it is suggested that even mundane social interactions can contribute to value (Holttinen, 2010), which will be discussed in the final section where perceived value is illustrated. In addition, as implied in the above quote and elaborated on in the next section, certain environmental settings and visitor characteristics can contribute to more profoundly perceived social interactions.

\section{Factors influencing C2C social interactions on social levels}

The previous section illustrated predictable and pattern-like manifestations of social interactions between visitors in a tourism context, determined and regulated by social structures including roles, repertoire of elements, sequences and rules, yet seemingly independent of underlying goals. When examining how social interactions could be categorized, it emerged that the three levels of social practice (see Figure 1) were inclusive of all examples as reflected upon during the interviews. Here, it becomes apparent that social practice is more complex, multilayered and versatile than the manifestation itself may suggest.

The first level as described by Rihova et al. $(2015$; 2013) is the communitas level, where previously unacquainted visitors create a temporary community by a shared sense of togetherness. Backpackers experienced communitas predominantly in shared accommodation settings, while other independent travellers reported to do so during organized activities. The main influential factor in creating this particular level was thus a restricted environmental setting (see Holloway, 1981; Tucker, 2005). Here, partcipants often experienced a certain obligation to converse with other visitors occupying the same space, attached to both the expectations of the tourist role and politeness. The combination of obligation, 'forced' togetherness, and stimulating experiential settings in the case of activities or an abundance of free time in shared accommodations, led to the possibility of longer interactions. The utilization of these possibilities was then strongly dependent upon personal resources and interaction partner relationship. Personal resources predominantly related to social attitudes, determining the willingness to participate in social interactions with other visitors (see Heimtun, 2011; Levy \& Getz, 2012). Mutual likeability and perceived commonalities were crucial components of a positive interaction partner relationship, in turn leading to more personal and private interaction contents aiding the creation of perceived unity.

Backpackers as single travellers consciously aimed to create communitas through interactions with other visitors due to the lack of stable social contact and support during their travels (see Reichenberger, 2016), while other independent travellers reported to partake in such interactions 
based on self-perceived extroversion. The interactions themselves expanded in length based on the time spent within the environmental setting, and the repertoire of elements was complemented by the discussion of prior ventures, current comparisons of perspectives, and the sense of excitement through sharing new experiences. The creation of communitas level social practice was also supported by shared skills and knowledge of interaction participants, such as language competencies and knowledge relating to the experiential setting and touristic context. Forced co-existence has thus emerged as a precondition for creating communitas social practice in co-creation, brought to life through successful instrumentalisation of personal resources and aided by positively perceived interaction partner relationships.

The social bubble level of social practice originally referred to co-creational interaction between members of the own travel group as opposed to previously unacquainted visitors - although these may also be invited into the social bubble (Rihova et al., 2013). As no families or larger travel groups were represented in the study, only little information emerged to shed light on social interactions within the social bubble level. However, participants within the age range of 40 years and older, travelling with their partner, frequently described situations where their particular bubble as determined by group constellation was enhanced through social interactions with other visitors. Motivated purely by intrinsic goals with the clear aim to enhance the bubble, and explained through the personal resource of individual traits in the form of sociability, interactions with other visitors were had regardless of the environmental setting.

I love talking to people and meeting new people, it's interesting and fun. We meet people everywhere we go really, we're just social people. I'm travelling with my husband and it's always fun to have someone else to talk to, not always the same person for such a long time.

Female, Germany

Although communitas level interactions were described to be longer and often more personal, social bubble level interactions did not necessarily fulfil this criteria and were most frequently described as short interactional 'snippets', impacted predominantly by individual traits in combination with group constellation.

The final social practice level of the detached tourist then refers to social interactions of single or couple visitors whose primary focus is privacy and relaxation with no particular aim to interact with others but a willingness to provide assistance (Rihova et al., 2013). Participants who reported to prefer social interactions within the detached tourist level were between 20 and 40 years old and travelling with their partner. Their social focus was predominantly on their companion, making personal resources in the form of group constellation and lower sociability the main influential factors for social interactions on this level. In addition, a preference for private transport and accommodation led to fewer environmental settings providing opportunities to interact with other visitors.

First of all, we don't meet that many people - we stay in hotels, we have a rental car, and we don't like organized tours so much. Also, there's only so much energy to go 
around and I prefer to spend that energy on my partner and not on strangers, to have those experiences with him.

Female, Germany

Interactions with other visitors as reported by those interacting within the detached tourist level were commonly motivated by the goal of politeness, seldom initiated but mostly responded to, short in duration and continuously focused on the sole exchange of travel related information. Single travellers did not report to interact on this level frequently due to their explicit preference for the communitas level. Only occasionally did some backpacker participants describe themselves as more detached, motivated by a decrease in personal resources in the form of energy and social tolerance.

Sometimes it's nice to just have a few days on your own. Not always, yeah, I really thought I wouldn't be, because I really like to talk to people, but [...] at home, you have that already, you're alone at home, and here you have people talking to you all day.

Female, Netherlands

Interactions on the detached tourist level were thus predominantly impacted by personal resources, more specifically individual traits in the form of sociability and energy.

\section{Perceived value through $C 2 C$ co-creation}

Depending on the level of social practice, most frequently determined and influenced by the environmental setting and personal resources in the form of personal traits relating to sociability, participants described different types of value stemming from the social interaction based co-creation with other visitors.

Not surprisingly, interactions on the communitas level were perceived to create the highest value for participants. The comparatively long timeframe, increase in personal elements, and the component of a shared and mutually enhanced lived experience were reported to have exclusively positive impacts. Emotional value was co-created through personal and long social interactions, in the case of single travellers other visitors often functioned as a replacement for the social support network (Reichenberger, 2016). Entertainment-related value was co-created through the enhancement of new and exciting occurrences via social interactions, where the process of sharing perspectives and viewpoints enriched the experience through providing enjoyment, fun, and information. This value sometimes went beyond the experiential interpretation of certain activities as it also contributed to self-actualization and the broadening of horizons through exposure to other cultures and viewpoints of interaction partners.

This is the first time we travelled outside of Europe, and meeting all these people from different places - you realize how much of you is, well, you and how much comes from (...) how you grow up, where you live. (...) It made me see things, it made me see me in another way (...), it changes me.

Female, Germany 
The underlying crucial requirement for a positively perceived value was, however, a positive interaction partner relationship based upon a mutual likeability and 'connection' in the form of commonalities - only then was the value created through social interactions with other visitors perceived as profound as opposed to superficial and transient.

It was quite profound really. This couple was kind of like a little bit of an older version of my husband and myself (...). And they were going into retirement, doing what we're doing now, wishing they had done it at our age. And so it was just a common bond of lifestyle and sense of adventure, and they were an important part of that tour.

Female, USA

The co-created value on communitas level was described as complex, multi-layered, and an integral part of participants' travels. Visitor-visitor social interactions on the social bubble level were, predictably, reported to co-create value on a less complex and personally significant level. Here, the bubble represented a travel group of usually two partners, with social interactions being determined by intrinsic goals based on sociability. It was previously suggested that interactions within the social bubble appeared short, superficial and often mundane in their manifestations, following predictable patterns with little personal elements. Although this type of social interaction, regardless of environmental setting, did not result in immediate co-created value relating to their specific context, their cumulative impact on the visitor experience with New Zealand had atmospheric value.

I think it's the (...) overall atmosphere that comes with these conversations, you know? People are so nice and friendly, and it happens again and again, we haven't met one single person who was rude, so it creates a certain type of positive atmosphere that contributes to your feelings about the place.

Male, USA

In addition, the strong focus on travel-related social interaction elements resulted in the cocreation of practical value for future travel behaviour. Although this was applicable to communitas social interactions as well, it was not a value-related impact emphasized by participants. Social bubble interactions however resulted in comparatively less complex value co-creation, thus increasing the importance of practical value. Recommendations and experiences from other visitors were regarded as an important source of information, subsequently influencing future travel decisions.

Not because it was such a memorable conversation, but because they gave us advice about where to go, where to eat, these little things that will eventually make part of our stay different to what it would have been otherwise.

Female, UK

Those interactions related to the detached tourist level, motivated not by intrinsic goals but most frequently by politeness, then resulted in practical co-created value only, where no further benefits were perceived from interacting with other visitors. 


\section{DISCUSSION AND CONCLUSION}

This paper aimed to identify the processes and influential factors of $\mathrm{C} 2 \mathrm{C}$ value co-creation in tourism with particular focus on the manifestations of social interactions underlying social practice on different levels and their resulting types of value. The components of Rihova et al.'s (2015) theoretical conceptualization were examined using extended social situation analysis, leading to detailed information on what the influential factors of personal resources, shared images, and social structures consist of and how they impact $\mathrm{C} 2 \mathrm{C}$ value co-creation. In addition, the three levels of social practice have been enhanced through illustrating how their manifestations of social interactions differ and the type of value that is co-created.

Social interactions between visitors as the core of value co-creation rely on social structures (repertoire of elements, sequences, rules) leading to inflexible and pre-determined processes, accepted by all participants due to their role as a tourist, and commonly shared images (concepts and cognitive structures) - understandings of what is deemed acceptable. This is applicable to all reported interactions regardless of their level, however the type of value that is co-created through often mundane and uniform interactions differs strongly dependent on the social level within which they occur.

Communitas level social interactions resulted in multiple types of co-created value, namely emotional, entertainment-related, self-actualization, and, to a less important extent, practical. The pivotal factors here were a restricted environmental setting within which a lived experience was shared. This forced togetherness, combined with personality traits (sociability) and intrinsic goals, led to the expansion of social interactions through more personal and weighty contents, inspired through personal resources (skills, knowledge, language) and a positive interaction partner relationship. Social bubble level interactions were similarly based upon intrinsic goals and the personality trait sociability, the absence of a restricted setting however hindered the development of more profound interactions. Nevertheless, social bubble interactions still cocreated entertainment-related and practical value as well as an overarching atmospheric value. Here, the individuals themselves and their social attitudes were found to be the main determinants of perception and experiential co-creation - becoming even more apparent when considering detached tourist level interactions. Although interactions on both the social bubble and the detached tourist level differed little in regards to their actual manifestations, participants' personal traits limited the effect of co-creation to practical value only. Less importance was assigned to social contacts, predominantly motivated by obligation, thus not allowing the more experiential and subjective types of value being performed.

This, in turn, suggests that a social interaction itself is not the determinant of co-created value but solely a tool that, utilized under favourable circumstances (including environment, personal traits, goals, interaction partner relationship), can aid the subjective and experiential value cocreation as perceived by visitors. Although all features of extended social situation analysis structure, shape and influence occurrence and process of social interactions, it is the individual visitor whose social attitude is the deciding factor in determining the type of perceived value that is co-created. In summary, value is created through but not necessarily because of social interactions. While circumstances of social interactions can encourage and support the cocreation of value, it is the individual who is at the core of the construct (as suggested by Heimtun, 2011; Levy \& Getz, 2012; Quiroga, 1990). This is in line with social constructivism's 
assumption that meaning is dependent upon individuals (Lincoln et al., 2011; Pernecky, 2012) and re-emphasizes the views of Pearce (2005b) and Crouch et al. (2004) that it is tourists themselves who create an experience.

Findings of this research have several implications, especially for the further research of value co-creation in tourism from an industry perspective. Prior research has only marginally been concerned with the individuals co-creating experiences, focusing predominantly on the role of the service provider. However, this research shows that this role may be overestimated in its contribution to and facilitation of value co-creation, and attention should be shifted towards a more holistic and psychologically founded approach to better understand how to create circumstances for different types of customers that allow them to co-create the type of value they assign importance to.

For example, spaces shared by visitors should be designed in a way that provides opportunities for visitors to engage in interaction if they wish - utilizing means of design, facilities, prompts, services or personnel. Especially restricted environmental settings emerged as a factor encouraging the co-creation of multiple types of value. Guided tours were one example of these settings, implying that the providers of guided tours may consider targeted facilitation of social interactions between visitors themselves to add value to their experience. Similarly, shared accommodation providers may consider barrier-free designs to ensure that social interactions are able to occur, while simultaneously providing services that allow visitors to remain within the setting and thus interaction. However, not all visitors place value upon interacting with others. Although no negative interaction-based impacts emerged throughout this research, heterogeneity amongst visitors in terms of sociability must be acknowledged and catered for.

Further research on this topic may examine the interplay between and roles of different social actors within a setting so as to provide a comparative analysis of the roles of the own travel group, other visitors, service personnel, host community etc. within value co-creation. Especially the social interactions within the social bubble and detached tourist level require additional attention that also considers individual motivations and group dynamics in different touristic contexts. Social interactions within the communitas level of social practice implied differences between travel forms and a potentially strong impact of travel behaviour, calling for a comprehensive analysis of activities and restricted tourism settings to further illustrate the role of participation and its influential factors. Especially a focus on internally vs. externally oriented activities and a deeper insight into the complexities within specific settings will contribute to a more thorough and analytical understanding of how contextual aspects contribute to value cocreation. Limitations of this study should also be addressed, most specifically by examining value co-creation for members of larger groups and families. Destinations that appeal to different visitor types and/or encourage more static travel behaviour may also differ in the manifestations of social practice and resulting types of value, and further insight is needed to extract the impact of demographic and cultural factors. 


\section{REFERENCES}

Andrades, L., \& Dimanche, F. (2014). Co-creation of experience value: a tourist behaviour approach. In N. K. Prebensen, J. S. Chen, \& M. Uysal (Eds.), Creating experience value in tourism (pp. 95-112). Wallingford: CABI International.

Argyle, M., Furnham, A., \& Graham, J. A. (1981). Social situations. Cambridge: Cambridge University Press.

Au, K. H. (1998). Social Constructivism and the School Literacy Learning of Students of Diverse Backgrounds. Journal of Literacy Research, 30(2), 297-319.

Baron, S., Harris, K., \& Davies, B. J. (1996). Oral participation in retail service delivery: a comparison of the roles of contact personnel and customers. European Journal of Marketing, 30(9), 75-90.

Becken, S., \& Gnoth, J. (2004). Tourist consumption systems among overseas visitors: Reporting on American, German, and Australian visitors to New Zealand. Tourism Management, 25(3), 375-385.

Cabiddu, F., Lui, T.-W., \& Piccoli, G. (2013). Managing Value Co-Creation in the Tourism Industry. Annals of Tourism Research, 42, 86-107.

Campos, A. C., Mendes, J., do Valle, P. O., \& Scott, N. (2015). Co-creation of tourist experiences: a literature review. Current Issues in Tourism, 1-32.

Campos, A. C., Mendes, J., do Valle, P. O., \& Scott, N. (2016). Co-Creation Experiences: Attention and Memorability. Journal of Travel \& Tourism Marketing, 33(9), 13091336.

Cohen, E. (1972). Toward a sociology of international tourism. Social Research, 39(1), 164182.

Crouch, D., Aronsson, L., \& Wahlstrom, L. (2004). Tourist encounters. In S. Williams (Ed.), Tourism. Critical Concepts in the Social Sciences (Vol. 2, pp. 278-295). London, New York: Routledge.

Cutler, S. Q., \& Carmichael, B. A. (2010). The dimensions of the tourist experience. In M. Morgan, P. Lugosi, \& J. R. B. Ritchie (Eds.), The tourism and leisure experience: Consumer and managerial perspectives (pp. 3-26). Bristol: Channel View Publications.

Fisher, R. J., \& Price, L. L. (1991). International pleasure travel motivations and post-vacation cultural attitude change. Journal of Leisure Research, 20(2), 10-16.

Goffman, E. (1967). Interaction ritual. Essays on face-to-face behaviour. London: Allen Lane The Penguin Press.

Grove, S. J., \& Fisk, R. P. (1997). The impact of other customers on service experiences: A critical incident examination of "getting along". Journal of Retailing, 73(1), 63-85.

Harris, K., \& Baron, S. (2004). Consumer-to-consumer conversations in service settings. Journal of Service Research, 6(3), 287-303.

Heimtun, B. (2011). The group package tour and sociability: Contesting meanings. Tourism Review International, 14(1), 3-15. 
Holbrook, M. B. (1999). Introduction to consumer value. In M. B. Holbrook (Ed.), Consumer Value. A framework for analysis and research (pp. 1-28). London: Routledge.

Hollinshead, K. (2006). The Shift to Constructivism in Social Inquiry: Some Pointers for Tourism Studies. Tourism Recreation Research, 31(2), 43-58.

Holloway, J. C. (1981). The guided tour: A sociological approach. Annals of Tourism Research, $8(3), 377-402$.

Holttinen, H. (2010). Social practices as units of value creation: theoretical underpinnings and implications. International Journal of Quality and Service Sciences, 2(1), 95-112.

Huang, J., \& Hsu, C. H. C. (2010). The impact of customer-to-customer interaction on cruise experience and vacation satisfaction. Journal of Travel Research, 49(1), 79-92.

Levy, S. E., \& Getz, D. (2012). An exploration of social stimuli influencing the student sightseeing tour experience. Tourism Review International, 15(4), 297-311.

Li, X., \& Petrick, J. F. (2008). Tourism Marketing in an Era of Paradigm Shift. Journal of Travel Research, 46(3), 235-244.

Lincoln, Y. S., Lynham, S. A., \& Guba, E. G. (2011). Paradigmatic Controversies, Contradictions, and Emerging Confluences, Revisited. In N. K. Denzin \& Y. S. Lincoln (Eds.), The SAGE Handbook of Qualitative Research (pp. 97-128). Los Angeles: SAGE.

Loker-Murphy, L., \& Pearce, P. L. (1995). Young budget travelers: Backpackers in Australia. Annals of Tourism Research, 22(4), 819-843.

Mathis, E. F., Kim, H., Uysal, M., Sirgy, J. M., \& Prebensen, N. K. (2016). The effect of cocreation experience on outcome variable. Annals of Tourism Research, 57, 62-75.

Maunier, C., \& Camelis, C. (2013). Toward an identification of elements contributing to satisfaction with the tourism experience. Journal of Vacation Marketing, 19(19), 19-39.

McGrath, M. A., \& Otnes, C. (1995). Unacquainted influencers: When strangers interact in the retail setting. Journal of Business Research, 32(3), 261-272.

Mossberg, L. (2007). A marketing approach to the tourist experience. Scandinavian Journal of Hospitality and Tourism, 7(1), 59-74.

Murphy, L. (2001). Exploring social interactions of backpackers. Annals of Tourism Research, $28(1), 50-67$.

Neuhofer, B. (2016). Value co-creation and co-destruction in conneced tourist experiences. Paper presented at the ENTER 2016, Bilbao, Spain.

Nicholls, R. (2010). New directions for customer-to-customer interaction research. Journal of Services Marketing, 24(1), 87-97.

Papathanassis, A. (2012). Guest-to-guest interaction on board cruise ships: Exploring social dynamics and the role of situational factors. Tourism Management, 33(5), 1148-1158.

Parker, C., \& Ward, P. (2000). An analysis of role adoptions and scripts during customer-tocustomer encounters. European Journal of Marketing, 34(3/4), 341-358. 
Pearce, P. L. (1984). Tourist-guide interaction. Annals of Tourism Research, 11(1), 129-146.

Pearce, P. L. (1990). Farm tourism in New Zealand: A social situation analysis. Annals of Leisure Research, 17(3), 337-352.

Pearce, P. L. (2005a). The role of relationships in the tourist experience. In W. F. Theobald (Ed.), Global tourism (3 ed., pp. 103-122). Amsterdam: Elsevier.

Pearce, P. L. (2005b). Tourist behaviour. Themes and conceptual schemes. Clevedon: Channel View Publications.

Pernecky, T. (2012). Constructionism. Critical Pointers for Tourism Studies. Annals of Tourism Research, 39(2), 1116-1137.

Prahalad, C. K., \& Ramaswamy, V. (2004). Co-creation experiences: The next practice in value creation. Journal of Interactive Marketing, 18(3), 5-14.

Prebensen, N. K., \& Foss, L. (2011). Coping and Co-creating in Tourist Experiences. International Journal of Tourism Research, 13(1), 54-67.

Prebensen, N. K., Vitters $\varnothing$, J., \& Dahl, T. I. (2013). Value Co-Creation Significance of Tourist Resources. Annals of Tourism Research, 42, 240-261.

Quiroga, I. (1990). The characteristics of package tours in Europe. Annals of Tourism Research, $17(2), 185-207$.

Reichenberger, I. (2016). Why the host community just isnt enough: Processes and impacts of backpacker social interactions. Tourist Studies.

Rihova, I., Buhalis, D., Moital, M., \& Gouthro, M.-B. (2015). Conceptualising Customer-tocustomer Value Co-creation in Tourism. International Journal of Tourism Research, 17(4), 356-363.

Rihova, I., Buhalis, D., Moital, M., \& Gouthro, M. B. (2013). Social layers of customer-tocustomer value co-creation. Journal of Service Management, 24(5), 553-566.

Ross, E. L. D., \& Iso-Ahola, S. E. (1991). Sightseeing tourists' motivation and satisfaction. Annals of Tourism Research, 18(2), 226-237.

Schuchat, M. G. (1983). Comforts of tour groups. Annals of Tourism Research, 10(4), 465-477.

Shaw, G., Bailey, A., \& Williams, A. (2011). Aspects of service-dominant logic and its implications for tourism management: Examples from the hotel industry. Tourism Management, 32(2), 207-214.

Small, J. (1999). Memory-work: a method for researching women's tourist experiences. Tourism Management, 20(1), 25-35.

Tan, S.-K., Kung, S.-F., \& Luh, D.-B. (2013). A Model of 'Creative Experience' in Creative Tourism. Annals of Tourism Research, 41, 153-174.

Tucker, H. (2005). Narratives of place and self: Differing experiences of package coach tours in New Zealand. Tourist Studies, 5(3), 267-282.

Vargo, S. L., \& Lusch, R. F. (2004). Evolving to a New Dominant Logic for Marketing. Journal of Marketing, 68(1), 1-17. 
Vargo, S. L., Maglio, P. P., \& Akaka, M. A. (2008). On value and value co-creation: A service systems and service logic perspective. European Management Journal, 26(3), 145-152.

Walls, A. R., \& Wang, Y. (2011). Experiential consumption and destination marketing. In Y. Wang \& A. Pizam (Eds.), Destination Marketing and Management. Theories and Applications (pp. 82-98). Wallingford: CABI.

Warde, A. (2005). Consumption and Theories of Practice. Journal of Consumer Culture, 5(2), 131-153.

World Tourism Organization. (2010). UNWTO tourism highlights 2010 edition. Madrid: UNWTO.

Wu, C. H.-J. (2007). The impact of customer-to-customer interaction and customer homogeneity on customer satisfaction in tourism service - The service encounter prospective. Tourism Management, 28(6), 1518-1528. 
Table 1: Enhanced features of social situations (adapted from Pearce, 1990, p. 342)

\begin{tabular}{|c|c|}
\hline Original Feature & Brief definition \\
\hline Environmental setting & $\begin{array}{l}\text { Environmental setting consists of the props, spaces, barriers, modifiers } \\
\text { which influence the situation. }\end{array}$ \\
\hline $\begin{array}{l}\text { Concepts and cognitive } \\
\text { structure }\end{array}$ & $\begin{array}{l}\text { Concepts and cognitive structures may be thought of as the shared } \\
\text { definitions and understandings needed to operate in the social situations. }\end{array}$ \\
\hline Roles & $\begin{array}{l}\text { Roles are the duties or obligations which attend the social positions } \\
\text { people occupy. }\end{array}$ \\
\hline $\begin{array}{l}\text { Repertoire of elements } \\
\text { (behaviours) }\end{array}$ & The sum of behaviours which are appropriate to that situation. \\
\hline Sequences & $\begin{array}{l}\text { The ordering of the repertoire of behaviours. Sequences may be very } \\
\text { fixed or very fluid. }\end{array}$ \\
\hline Rules & Rules are the shared beliefs which regulate behaviour. \\
\hline Language and speech & $\begin{array}{l}\text { How things are said, the code of speech, vocabulary, and social } \\
\text { variation inherent in language. }\end{array}$ \\
\hline Goals & Goals may be seen as the purpose or ends which direct social behaviour. \\
\hline Additional Feature & Brief definition \\
\hline Individual traits & $\begin{array}{l}\text { Personality traits including sociability, intro-/extroversion, social } \\
\text { attitudes. }\end{array}$ \\
\hline $\begin{array}{l}\text { Interaction partner } \\
\text { relationship }\end{array}$ & Characterised by mutual likeability, commonalities. \\
\hline
\end{tabular}


Table 2: Sample typology and characteristics (*multiple responses possible)

\begin{tabular}{|c|c|c|}
\hline & $\begin{array}{c}\text { Percentages } \\
\%\end{array}$ & $\begin{array}{c}\text { Count } \\
\text { N }\end{array}$ \\
\hline \multicolumn{3}{|l|}{ Age Group } \\
\hline $18-29$ & 58 & 44 \\
\hline $30-39$ & 21 & 16 \\
\hline $40-49$ & 5 & 4 \\
\hline 50 and over & 16 & 12 \\
\hline \multicolumn{3}{|l|}{ Area of Origin } \\
\hline Europe & 72 & 55 \\
\hline USA/Canada & 20 & 15 \\
\hline Australia/Oceania & 5 & 4 \\
\hline Other & 3 & 2 \\
\hline \multicolumn{3}{|l|}{ Length of Stay } \\
\hline Less than 4 weeks & 24 & 18 \\
\hline 4 weeks or longer & 76 & 58 \\
\hline \multicolumn{3}{|c|}{ Travel Group Constellation* } \\
\hline Single & 51 & 39 \\
\hline Partner & 36 & 27 \\
\hline Friends & 12 & 9 \\
\hline Family & 4 & 3 \\
\hline \multicolumn{3}{|l|}{ Transport Types* } \\
\hline Public bus network & 41 & 31 \\
\hline Rental car & 32 & 24 \\
\hline Campervan & 20 & 15 \\
\hline Backpacker bus & 17 & 13 \\
\hline \multicolumn{3}{|c|}{ Accommodation Types* } \\
\hline $\begin{array}{l}\text { Hostels } \\
\text { Hots }\end{array}$ & 66 & 50 \\
\hline Campsites & 25 & 19 \\
\hline Motels & 9 & 7 \\
\hline Hotels & 9 & 7 \\
\hline Friends/Family & 11 & 8 \\
\hline
\end{tabular}


Figure 1: C2C co-creation in tourism (adapted from Rihova et al., 2015, p. 360)

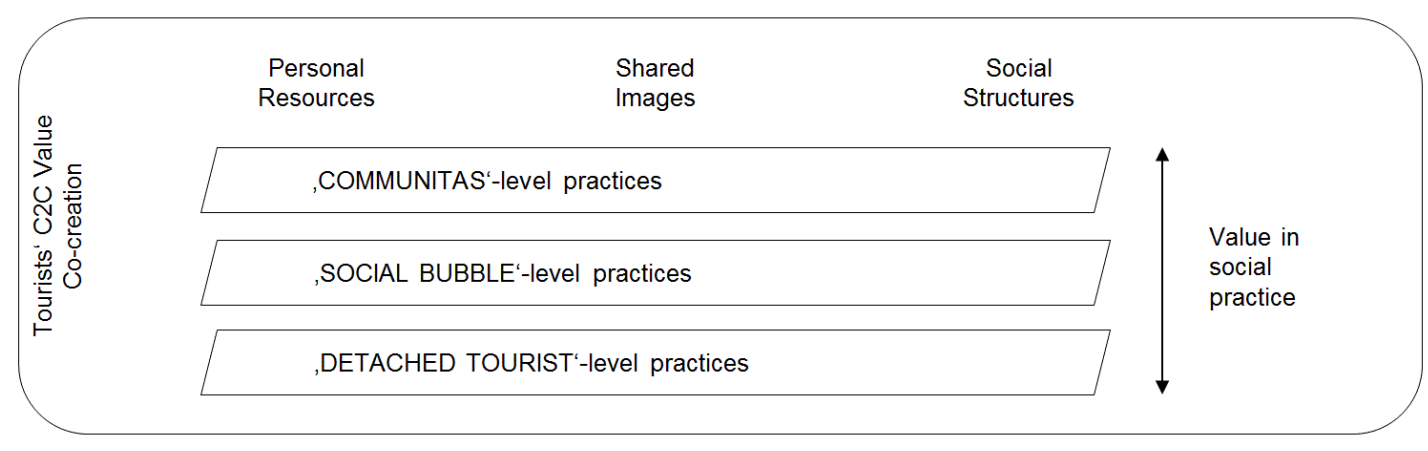

